\title{
High Risk of Readmission in Octogenarians Undergoing Primary Hip Arthroplasty
}

\author{
Arthur L. Malkani MD, Brian Dilworth MD, Kevin Ong PhD, \\ Doruk Baykal PhD, Edmund Lau MS, Theresa N. Mackin BA, \\ Gwo-Chin Lee MD
}

Published online: 12 January 2017

(C) The Association of Bone and Joint Surgeons( 2017

\begin{abstract}
Background As life expectancy increases, more elderly patients with end-stage hip arthritis are electing to undergo primary THA. Octogenarians undergoing THA have more comorbidities than younger patients, but this is not reflected in risk adjustment models for bundled care programs. The burden of care associated with THA in octogenarians has not been well characterized, and doing so may help these value-based programs make adjustments so that this vulnerable patient population does not risk losing access under accountable care models.
\end{abstract}

One or more of the authors (KO, DB, EL) are employees of Exponent, Inc.

All ICMJE Conflict of Interest Forms for authors and Clinical Orthopaedics and Related Research $\mathbb{\AA}$ editors and board members are on file with the publication and can be viewed on request.

This work was performed at the University of Louisville, Louisville, KY, USA; the University of Pennsylvania, Philadelphia, PA, USA; and at the offices of Exponent, Inc, Philadelphia, PA, USA, and Menlo Park, CA, USA.

\section{A. L. Malkani (}

Adult Reconstruction Program, KentuckyOne Health, University of Louisville, $550 \mathrm{~S}$ Jackson Street, First Floor, ACB, Louisville, KY 40202, USA

e-mail: arthur.malkani@louisville.edu

B. Dilworth

Department of Orthopedic Surgery, University of Louisville, Louisville, KY, USA

K. Ong

Exponent Inc, Philadelphia, PA, USA

D. Baykal, E. Lau

Exponent Inc, Menlo Park, CA, USA

T. N. Mackin, G.-C. Lee

University of Pennsylvania, Philadelphia, PA, USA
Questions/purposes The purpose of this study was to describe care use, comorbidities, and complications among octogenarians undergoing primary THA.

Methods Five percent of the Medicare national administrative claims data was queried to identify patients diagnosed with hip osteoarthritis between January 1, 1998, and December 31, 2013. Patients who underwent primary THA were identified and followed longitudinally during the study period using their unique, encrypted Medicare beneficiary identifiers. We compared risk factors and complications between the octogenarian group versus those aged 65 to 69 years. Multivariate Cox regression was used to evaluate the effect of patient/hospital factors on risk of revision, periprosthetic joint infection, dislocation, venous thromboembolism (VTE), and mortality. Patient factors in the model included age, sex, race, region, socioeconomic status, and health status based on Charlson comorbidity score 12 months before replacement surgery.

Results There were 11,960 THAs in the octogenarians in 1998, which increased to 21,620 in 2013, an $81 \%$ increase during this study period. Octogenarians were more likely to have a Charlson score of 3 or higher than those patients aged 65 to 69 years (30\% versus $17 \%$, odds ratio [OR] 2.07 [1.98-2.20]; $\mathrm{p}<0.001)$, and they were more likely to have coronary artery disease or congestive heart failure $(47 \%$ versus $29 \%$, OR 2.16 [2.06-2.26]; $\mathrm{p}<0.001)$. The octogenarian group had a greater risk of dislocation $(+12 \%, \mathrm{p}=$ $0.01)$, VTE $(+14 \%, \mathrm{p}<0.001)$, and mortality $(+150 \%, \mathrm{p}<$ $0.001)$ compared with the younger age cohort. A total of $21 \%$ of the octogenarians were readmitted after surgery compared with $12 \%$ for patients in the younger group $(\mathrm{OR}=1.64,95 \%$ confidence interval $1.54-1.75 ; \mathrm{p}<0.001)$. Conclusions Because octogenarians are at increased risk of dislocation, VTE, medical complications, and mortality after THA, value-based care models that penalize hospitals 
for readmissions and complications may inadvertently result in loss of access to care for this group of patients as a result of the financial makeup of these bundled care models. Value-based care models were developed to improve care and decrease healthcare costs but may have unintended consequences in the octogenarian with higher complication and readmission risks. Financial losses may lead to institutions from withdrawing from the Bundled Payments for Care Improvement program. To try to prevent this from happening to this vulnerable patient population, bundled care programs should evolve and be modified to allow for risk stratification in the overall payment formula to account for increased age and comorbid conditions to ensure continued successful participation in the program among all the stakeholders.

Level of Evidence Level III, therapeutic study.

\section{Introduction}

With greater life expectancy, the number of elderly persons continues to increase worldwide. Improvements in medical care along with increased life expectancy and the desire to maintain mobility and independence have resulted in an increased number of octogenarians and nonagenarians undergoing THA. The clinical benefit and improvement in quality outcome measures demonstrated in younger patients undergoing primary THA are also true in the elderly. Mota [12] demonstrated that primary THA is cost-effective in our aging population. The increased numbers of our elderly undergoing total joint arthroplasty places a burden on our healthcare system from a financial and resource perspective. In hopes to provide value-based health care to all patients undergoing total joint arthroplasty, the Centers for Medicare \& Medicaid Services (CMS) has enacted innovative strategies such as the Bundled Payments for Care Improvement (BPCI), which prompts hospitals and providers to be more accountable in the overall care episode for the patient. There are four different models of the BPCI program. The model that is commonly used consists of bundling the cost of the inpatient hospital stay along with 90 days of postoperative care. The institution participating in the BPCI is responsible for all costs incurred within the 90 days, including complications and readmissions.

With the advent of bundled payment models, institutions and providers are financially penalized for complications and readmission. Octogenarians in general have greater comorbid conditions and are at higher risk for complications and readmissions [5]. However, there are currently no risk adjustment models for patients with serious comorbidities undergoing THA. It seems important to calculate the care burden that octogenarians place on the healthcare system when they undergo THA; information on comorbidities, complications, and readmissions among octogenarians might help to guide risk adjustment models to better reflect the actual costs of care associated with this important but somewhat vulnerable patient population that may place a greater burden on the healthcare system.

The purpose of this study was to describe care use, comorbidities, and complications among octogenarians undergoing primary THA in an effort to identify specific risk factors that lead to increased readmissions and therefore overall healthcare costs.

\section{Materials and Methods}

Part A (inpatient services) of 5\% Medicare national administrative claims data was queried to identify patients diagnosed with hip osteoarthritis between January 1, 1998, and December 31, 2013. All fee-for-service claims submitted by the hospitals are included in this data set. We chose this database because given the unique number assigned to Medicare beneficiaries, they can be followed in a longitudinal fashion regardless of the treating institution or provider. The database is very robust and provides the requisite information for our purpose with significant power $[2,11]$.

International Classification of Diseases, 9th Revision, Clinical Modification (ICD-9-CM) diagnosis code 715.x5 were used to identify patients who were diagnosed with hip osteoarthritis. Patients undergoing primary THA were identified with ICD-9-CM procedure code 81.51. Patients with less than 12 months of history or beneficiaries enrolled in a health maintenance organization were excluded. Patients who were not enrolled in both Parts A and $\mathrm{B}$ of Medicare or patients younger than 65 years of age were excluded. Finally, beneficiaries residing outside of the 50 states were excluded. The octogenarian group was stratified from remaining age groups.

The patients were followed longitudinally during the study period using their unique, encrypted Medicare beneficiary identifiers. The average followup was 6 years (SD 4 years) with a median followup of 5.5 years (25th percentile: 2.6 years; 75 th percentile: 8.9 years). Mortality was monitored by a linked "denominator" file provided by the CMS with the analytical data sets. The outcomes of interest were identified by ICD-9-CM codes shown (Table 1). ICD9-CM code 453.42 for venous thromboembolic (VTE) disease was effective from October 2004, whereas diagnosis code 996.42 for hip dislocation and procedure codes 00.70 to 00.73 for revision THA were effective from 
October 2005. The rest of the codes were effective by the beginning of the study period.

Multivariate Cox regression was used to evaluate the effect of patient/hospital factors on risk of revision/ arthrotomy, prosthetic joint infection (PJI), dislocation, VTE, and mortality. The Cox model combined the likelihood functions from each confounding factor and estimated an overall event ratio and corresponding confidence intervals. Patient factors in the model included age, sex, race, region, socioeconomic status (Medicare buy-in status was used as proxy; this represents state subsidy for the Medicare premium), health status based on Charlson comorbidity score, diagnoses of diabetes (250.xx), obesity (V85.3x, V85.4x, and 278.0x), and heart disease (410-414, and 428) in 12 months before replacement surgery. Hospital/clinical variables included hospital size (number of beds), hospital control (nonprofit, private, public), hospital location (rural, urban), hospital type (teaching, community), and year of surgery. The type of hip osteoarthritis diagnosis was also included as a covariate. Year-squared was also added as a covariate to adjust for any nonlinearity in year. Competing risk resulting from death was accounted for in the analysis. Death before the end of the study and without first observing the event of interest was defined as a form of censoring resulting from competing risk. The hazard-specific Cox modeling approach was used in the analysis and competing risk censoring was specifically indicated in the model for proper handling. Statistical analysis was performed using SAS statistical software (Version 9.4; Cary, NC, USA).

\section{Results}

During the study period 1998 to 2013, there was an $81 \%$ increase in the incidence of primary THA in the octogenarian population (Fig. 1). Octogenarians were more likely to have a Charlson score of 3 or higher than those patients aged 65 to 69 years (30\% versus $17 \%$, odds ratio [OR] 2.07 [1.98-2.20]; $\mathrm{p}<0.001)$, and they were more likely to have coronary artery disease or congestive heart failure (47\% versus 29\%, OR 2.16 [2.06-2.26]; p < 0.001) (Fig. 2). With increasing age, the proportion of patients discharged to home (with or without home health services) decreased,

Table 1. Demographic breakdown of primary THA cohort

\begin{tabular}{|c|c|c|c|c|c|}
\hline Demographic & $65-69$ years $(n=16,869)$ & $70-74$ years $(n=18,601)$ & $75-79$ years $(n=16,671)$ & $80-89$ years $(n=14,650)$ & $90+$ years $(n=686)$ \\
\hline \multicolumn{6}{|l|}{ Gender } \\
\hline Female & $58 \%$ & $61 \%$ & $64 \%$ & $68 \%$ & $78 \%$ \\
\hline \multicolumn{6}{|l|}{ Race } \\
\hline White & $93 \%$ & $94 \%$ & $95 \%$ & $96 \%$ & $96 \%$ \\
\hline Black & $6 \%$ & $5 \%$ & $4 \%$ & $3 \%$ & $2 \%$ \\
\hline \multicolumn{6}{|l|}{ Census region } \\
\hline Midwest & $29 \%$ & $30 \%$ & $30 \%$ & $31 \%$ & $31 \%$ \\
\hline Northeast & $18 \%$ & $19 \%$ & $20 \%$ & $20 \%$ & $20 \%$ \\
\hline South & $34 \%$ & $34 \%$ & $32 \%$ & $31 \%$ & $29 \%$ \\
\hline West & $19 \%$ & $18 \%$ & $18 \%$ & $18 \%$ & $21 \%$ \\
\hline \multicolumn{6}{|l|}{ Charlson score } \\
\hline 0 & $43 \%$ & $38 \%$ & $32 \%$ & $27 \%$ & $22 \%$ \\
\hline $1-2$ & $40 \%$ & $42 \%$ & $42 \%$ & $43 \%$ & $44 \%$ \\
\hline $3-4$ & $12 \%$ & $15 \%$ & $18 \%$ & $22 \%$ & $23 \%$ \\
\hline $5+$ & $5 \%$ & $5 \%$ & $7 \%$ & $8 \%$ & $11 \%$ \\
\hline \multicolumn{6}{|c|}{ Medicare buy-in (state subsidy for insurance) } \\
\hline Yes & $7 \%$ & $6 \%$ & $6 \%$ & $6 \%$ & $8 \%$ \\
\hline \multicolumn{6}{|l|}{ Diabetic } \\
\hline Yes & $23 \%$ & $23 \%$ & $23 \%$ & $21 \%$ & $18 \%$ \\
\hline \multicolumn{6}{|l|}{ Obesity } \\
\hline Yes & $19 \%$ & $14 \%$ & $10 \%$ & $6 \%$ & $3 \%$ \\
\hline \multicolumn{6}{|l|}{ Heart failure } \\
\hline Yes & $29 \%$ & 34.0 & $41 \%$ & $47 \%$ & $51 \%$ \\
\hline
\end{tabular}


Fig. 1 The incidence of THA showed an $81 \%$ increase in the octogenarian population during the study period.

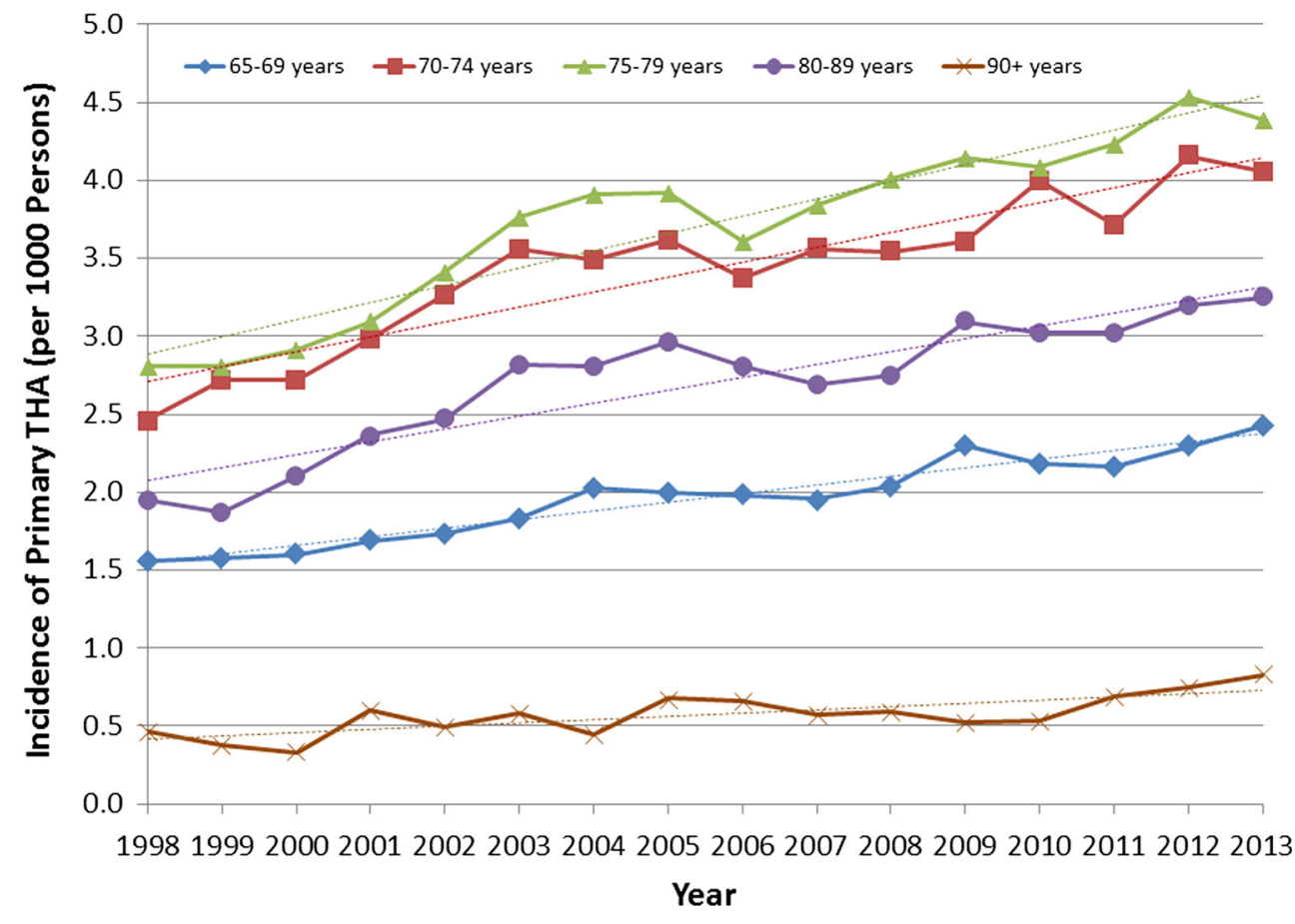

Fig. 2 Octogenarians are more likely to have a high Charlson score.

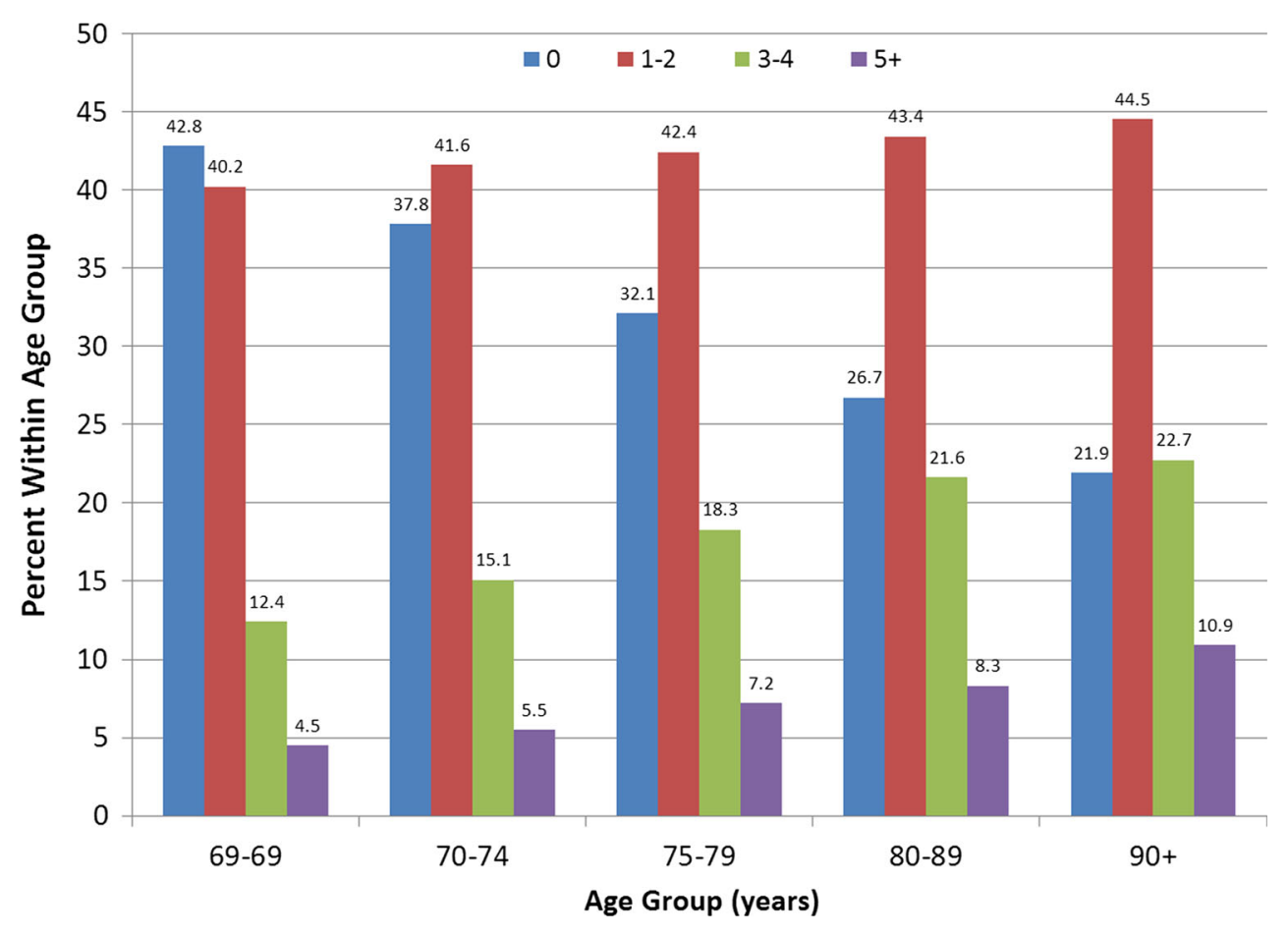

whereas more patients in the older age groups were discharged to rehabilitation facilities or skilled nursing facilities (Fig. 3).

The octogenarian group had a greater adjusted risk of dislocation $(+16 \%$; $95 \%$ confidence interval $[\mathrm{CI}] 4 \%-$ $30 \% ; \mathrm{p}=0.006)$, VTE $(+30 \% ; 95 \%$ CI $22 \%-37 \%$; $\mathrm{p}<$
0.001 ), and mortality (+385\%; $95 \%$ CI 357\%-400\%; p < $0.001)$ at 10 years compared with the younger $65-$ to 69 year cohort (Table 2). The 65- to 69-year-old cohort had a $31 \%$ higher revision risk $(95 \%$ CI $16 \%-48 \%$; $<<0.001)$ but no difference in infection risk $(-3 \%$; $95 \% \mathrm{CI}-13 \%$ to $+9 \% ; \mathrm{p}=0.638$ ) compared with the octogenarian group at 
Fig. 3 With increasing age, the proportion of patients discharged to home (with or without home health services) decreased. HHS = home health services; $\mathrm{SNF}=$ skilled nursing facility.

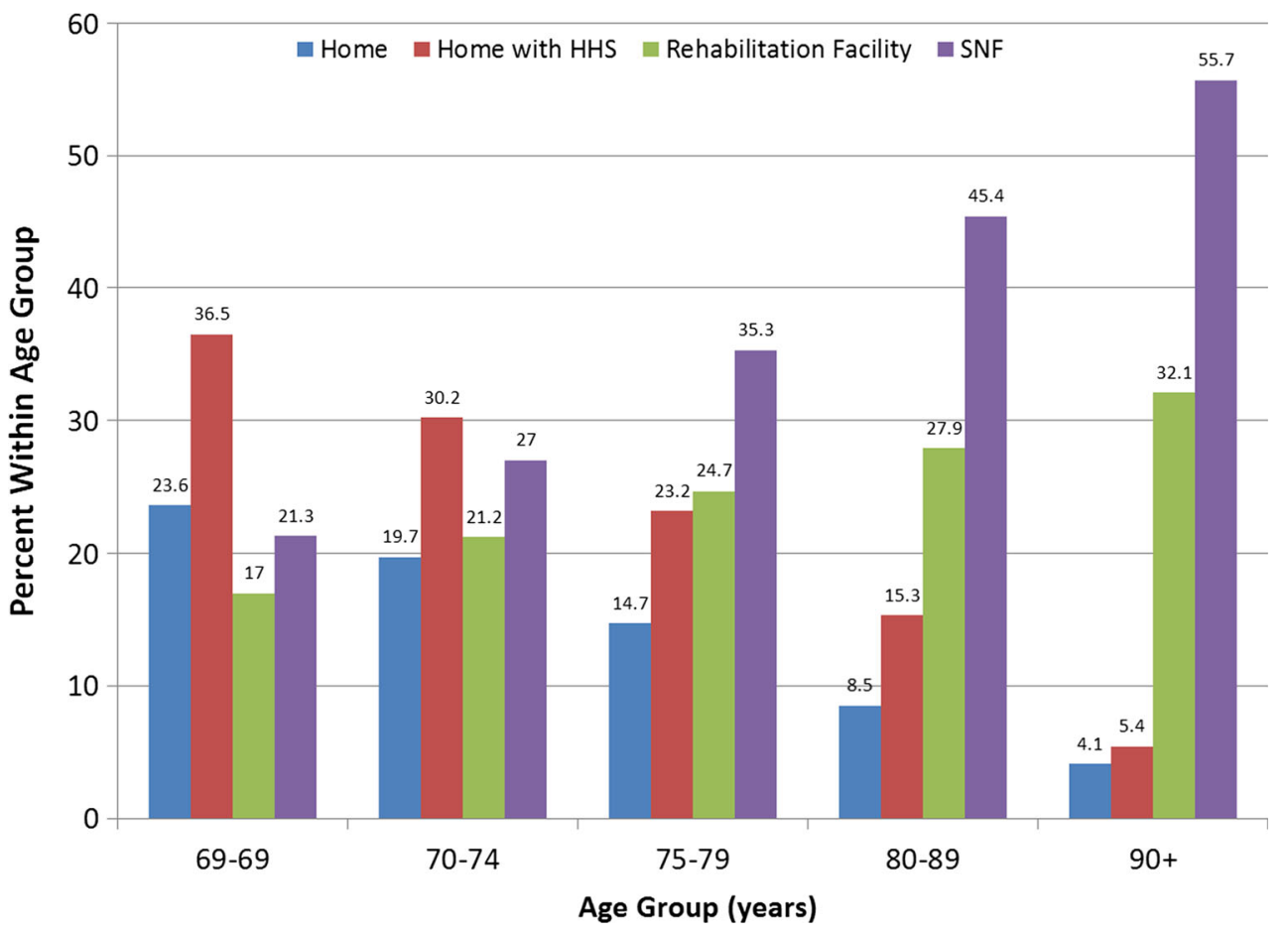

10 years. The risk of VTE and dislocation was higher for octogenarians compared with the 65- to 69- and 70- to 74year-old cohorts at all time points. The risk of mortality was higher for octogenarians compared with all the younger cohorts at all time points. A total of $21 \%$ of the octogenarians were readmitted within 90 days of surgery compared with $12 \%$ for patients in the younger (65-69 years of age) group (OR 1.64, 95\% CI 1.54-1.75; p < 0.001; Fig. 4). No association was found between the type of osteoarthritis (primary or secondary) and the outcomes. Kaplan-Meier survival analysis showed that at 10 years, approximately $25 \%$ of octogenarians (95\% CI $26 \%-27 \%$ ) had VTE compared with $20 \%$ of patients in the 65- to 69year cohort (95\% CI $19 \%-21 \%$; $<<0.001)$. Finally, at 10 years, $7.1 \%$ of octogenarians $(95 \%$ CI $6.6 \%-7.6 \%)$ had dislocation compared with $6.1 \%$ of patients in the $65-$ to 69 -year cohort (95\% CI 5.7\%-6.5\%; $p=0.006$; Fig. 5).

\section{Discussion}

As life expectancy increases, more elderly patients are undergoing primary THA to alleviate pain to continue their activities of daily living and enjoy quality of life. Levy et al. [9] showed that $88 \%$ of patients older than 80 years of age after primary THA were community ambulators at long-term followup. The Charnley hip scoring system, Harris hip scores, Merle d'Aubigne system, and WOMAC scores have consistently shown improved results after primary THA in older patients when compared with arthritic younger patients undergoing the same procedure $[6,7,9,10,15,17,19]$. However, concerns about the safety and increased complications remain in the elderly undergoing primary THA; this is especially important in the bundled payment era in which institutions and providers are financially responsible for complications and readmissions. However, in the elderly patient, despite medical management, increased complications and readmissions are likely the result of the comorbid conditions in this higher risk group. We compared complications and readmission incidence between the octogenarian group and a younger cohort during the same time period. The octogenarian group had increased complications with respect to VTE, dislocation, and infection leading to increased readmission incidence. During our study period, there was an approximately $81 \%$ increase in the number of octogenarians undergoing primary THA.

This study has several limitations. First, the data set represents only 5\% of the Medicare inpatient administrative claims sample. This may introduce information and sampling biases. Limitations with the database also include the lack of laterality information. However, this data set has been validated in other studies evaluating trends over time and, therefore, we believe that these observations are accurate $[2,14]$. Furthermore, this $5 \%$ sample is based on a systematic but randomized sample of the entire Medicare population based on selected digits in the beneficiary's insurance claim number. 
Table 2. Risk for clinical outcomes grouped by age

\begin{tabular}{|c|c|c|c|c|c|c|c|}
\hline Outcome & Factor $\mathrm{p}$ value & Level (years) & Risk of events & HR & Lower HR & Upper HR & Level $\mathrm{p}$ value \\
\hline \multicolumn{8}{|l|}{ Mortality } \\
\hline \multirow[t]{5}{*}{0.5 years } & $<0.001$ & $65-69$ & $0.61 \%$ & 0.35 & 0.28 & 0.44 & $<0.001$ \\
\hline & & $70-74$ & $0.85 \%$ & 0.41 & 0.34 & 0.50 & $<0.001$ \\
\hline & & $75-79$ & $1.3 \%$ & 0.56 & 0.46 & 0.67 & $<0.001$ \\
\hline & & $80-89$ & $2.3 \%$ & \multicolumn{4}{|c|}{ Reference group } \\
\hline & & $90+$ & $5.6 \%$ & 2.99 & 2.20 & 4.03 & $<0.001$ \\
\hline \multirow[t]{5}{*}{1 year } & $<0.001$ & $65-69$ & $1.1 \%$ & 0.36 & 0.31 & 0.43 & $<0.001$ \\
\hline & & $70-74$ & $1.5 \%$ & 0.44 & 0.38 & 0.51 & $<0.001$ \\
\hline & & $75-79$ & $2.2 \%$ & 0.55 & 0.48 & 0.64 & $<0.001$ \\
\hline & & $80-89$ & $4.0 \%$ & \multicolumn{4}{|c|}{ Reference group } \\
\hline & & $90+$ & $9.6 \%$ & 2.77 & 2.17 & 3.53 & $<0.001$ \\
\hline \multirow[t]{5}{*}{2 years } & $<0.001$ & $65-69$ & $2.3 \%$ & 0.36 & 0.31 & 0.40 & $<0.001$ \\
\hline & & $70-74$ & $3.1 \%$ & 0.44 & 0.39 & 0.49 & $<0.001$ \\
\hline & & $75-79$ & $4.6 \%$ & 0.57 & 0.52 & 0.63 & $<0.001$ \\
\hline & & $80-89$ & $8.2 \%$ & \multicolumn{4}{|c|}{ Reference group } \\
\hline & & $90+$ & $19 \%$ & 2.79 & 2.30 & 3.38 & $<0.001$ \\
\hline \multirow[t]{5}{*}{5 years } & $<0.001$ & $65-69$ & $7.7 \%$ & 0.31 & 0.29 & 0.33 & $<0.001$ \\
\hline & & $70-74$ & $11 \%$ & 0.39 & 0.37 & 0.42 & $<0.001$ \\
\hline & & $75-79$ & $15 \%$ & 0.54 & 0.52 & 0.58 & $<0.001$ \\
\hline & & $80-89$ & $25 \%$ & \multicolumn{4}{|c|}{ Reference group } \\
\hline & & $90+$ & $50 \%$ & 2.46 & 2.16 & 2.80 & $<0.001$ \\
\hline \multirow[t]{5}{*}{10 years } & $<0.001$ & $65-69$ & $24 \%$ & 0.26 & 0.25 & 0.28 & $<0.001$ \\
\hline & & $70-74$ & $31 \%$ & 0.37 & 0.35 & 0.38 & $<0.001$ \\
\hline & & $75-79$ & $42 \%$ & 0.55 & 0.53 & 0.57 & $<0.001$ \\
\hline & & $80-89$ & $60 \%$ & \multicolumn{4}{|c|}{ Reference group } \\
\hline & & $90+$ & $87 \%$ & 2.51 & 2.26 & 2.79 & $<0.001$ \\
\hline \multicolumn{8}{|l|}{ VTE } \\
\hline \multirow[t]{5}{*}{0.5 years } & $<0.001$ & $65-69$ & $5.3 \%$ & 0.73 & 0.66 & 0.81 & $<0.001$ \\
\hline & & $70-74$ & $6.0 \%$ & 0.79 & 0.72 & 0.88 & $<0.001$ \\
\hline & & $75-79$ & $6.6 \%$ & 0.94 & 0.86 & 1.03 & 0.188 \\
\hline & & $80-89$ & $6.8 \%$ & \multicolumn{4}{|c|}{ Reference group } \\
\hline & & $90+$ & $7.8 \%$ & 1.06 & 0.80 & 1.40 & 0.692 \\
\hline \multirow[t]{5}{*}{1 year } & $<0.001$ & $65-69$ & $6.4 \%$ & 0.74 & 0.68 & 0.82 & $<0.001$ \\
\hline & & $70-74$ & $7.2 \%$ & 0.82 & 0.75 & 0.90 & $<0.001$ \\
\hline & & $75-79$ & $7.9 \%$ & 0.95 & 0.88 & 1.03 & 0.208 \\
\hline & & $80-89$ & $8.2 \%$ & \multicolumn{4}{|c|}{ Reference group } \\
\hline & & $90+$ & $9.4 \%$ & 1.15 & 0.89 & 1.49 & 0.297 \\
\hline \multirow[t]{5}{*}{2 years } & $<0.001$ & $65-69$ & $8.1 \%$ & 0.76 & 0.70 & 0.83 & $<0.001$ \\
\hline & & $70-74$ & $9.1 \%$ & 0.86 & 0.79 & 0.93 & $<0.001$ \\
\hline & & $75-79$ & $10 \%$ & 0.97 & 0.90 & 1.05 & 0.474 \\
\hline & & $80-89$ & $10 \%$ & \multicolumn{4}{|c|}{ Reference group } \\
\hline & & $90+$ & $12 \%$ & 1.17 & 0.94 & 1.46 & 0.160 \\
\hline \multirow[t]{5}{*}{5 years } & $<0.001$ & $65-69$ & $13 \%$ & 0.78 & 0.73 & 0.83 & $<0.001$ \\
\hline & & $70-74$ & $14 \%$ & 0.87 & 0.81 & 0.93 & $<0.001$ \\
\hline & & $75-79$ & $16 \%$ & 0.98 & 0.92 & 1.04 & 0.458 \\
\hline & & $80-89$ & $16 \%$ & \multicolumn{4}{|c|}{ Reference group } \\
\hline & & $90+$ & $18 \%$ & 1.19 & 0.98 & 1.45 & 0.083 \\
\hline
\end{tabular}


Table 2. continued

\begin{tabular}{|c|c|c|c|c|c|c|c|}
\hline Outcome & Factor $\mathrm{p}$ value & Level (years) & Risk of events & HR & Lower HR & Upper HR & Level $p$ value \\
\hline \multirow[t]{5}{*}{10 years } & $<0.001$ & $65-69$ & $20 \%$ & 0.77 & 0.73 & 0.82 & $<0.001$ \\
\hline & & $70-74$ & $22 \%$ & 0.87 & 0.82 & 0.93 & $<0.001$ \\
\hline & & $75-79$ & $24 \%$ & 0.96 & 0.91 & 1.02 & 0.223 \\
\hline & & $80-89$ & $25 \%$ & \multicolumn{2}{|c|}{ Reference group } & & \\
\hline & & $90+$ & $28 \%$ & 1.15 & 0.95 & 1.40 & 0.142 \\
\hline \multicolumn{8}{|l|}{ Dislocation } \\
\hline \multirow[t]{5}{*}{0.5 years } & $<0.001$ & $65-69$ & $2.2 \%$ & 0.73 & 0.63 & 0.85 & $<0.001$ \\
\hline & & $70-74$ & $2.3 \%$ & 0.71 & 0.62 & 0.82 & $<0.001$ \\
\hline & & $75-79$ & $2.4 \%$ & 0.84 & 0.74 & 0.96 & 0.010 \\
\hline & & $80-89$ & $2.6 \%$ & \multicolumn{3}{|c|}{ Reference group } & \\
\hline & & $90+$ & $2.8 \%$ & 1.23 & 0.81 & 1.85 & 0.329 \\
\hline \multirow[t]{5}{*}{1 year } & $<0.001$ & $65-69$ & $2.6 \%$ & 0.75 & 0.65 & 0.86 & $<0.001$ \\
\hline & & $70-74$ & $2.6 \%$ & 0.75 & 0.66 & 0.85 & $<0.001$ \\
\hline & & $75-79$ & $2.8 \%$ & 0.80 & 0.71 & 0.91 & $<0.001$ \\
\hline & & $80-89$ & $3.0 \%$ & \multicolumn{2}{|c|}{ Reference group } & & \\
\hline & & $90+$ & $3.2 \%$ & 1.07 & 0.71 & 1.61 & 0.757 \\
\hline \multirow[t]{5}{*}{2 years } & 0.002 & $65-69$ & $3.1 \%$ & 0.81 & 0.71 & 0.92 & 0.001 \\
\hline & & $70-74$ & $3.2 \%$ & 0.81 & 0.72 & 0.91 & $<0.001$ \\
\hline & & $75-79$ & $3.4 \%$ & 0.85 & 0.75 & 0.95 & 0.005 \\
\hline & & $80-89$ & $3.6 \%$ & \multicolumn{2}{|c|}{ Reference group } & & \\
\hline & & $90+$ & $3.9 \%$ & 1.05 & 0.69 & 1.59 & 0.822 \\
\hline \multirow[t]{5}{*}{5 years } & 0.012 & $65-69$ & $4.4 \%$ & 0.85 & 0.75 & 0.95 & 0.005 \\
\hline & & $70-74$ & $4.5 \%$ & 0.84 & 0.76 & 0.94 & 0.002 \\
\hline & & $75-79$ & $4.7 \%$ & 0.87 & 0.78 & 0.97 & 0.010 \\
\hline & & $80-89$ & $5.1 \%$ & \multicolumn{2}{|c|}{ Reference group } & & \\
\hline & & $90+$ & $5.4 \%$ & 1.00 & 0.68 & 1.47 & 0.994 \\
\hline \multirow[t]{5}{*}{10 years } & 0.026 & $65-69$ & $6.1 \%$ & 0.86 & 0.77 & 0.96 & 0.006 \\
\hline & & $70-74$ & $6.2 \%$ & 0.87 & 0.79 & 0.96 & 0.007 \\
\hline & & $75-79$ & $7.5 \%$ & 0.92 & 0.84 & 1.01 & 0.093 \\
\hline & & $80-89$ & $7.1 \%$ & \multicolumn{2}{|c|}{ Reference group } & & \\
\hline & & $90+$ & $7.5 \%$ & 1.06 & 0.73 & 1.54 & 0.756 \\
\hline \multicolumn{8}{|l|}{ Infection } \\
\hline \multirow[t]{5}{*}{0.5 years } & 0.006 & $65-69$ & $1.4 \%$ & 0.77 & 0.63 & 0.94 & 0.012 \\
\hline & & $70-74$ & $1.4 \%$ & 0.92 & 0.76 & 1.10 & 0.358 \\
\hline & & $75-79$ & $1.4 \%$ & 0.84 & 0.69 & 1.02 & 0.086 \\
\hline & & $80-89$ & $1.4 \%$ & \multicolumn{2}{|c|}{ Reference group } & & \\
\hline & & $90+$ & $1.9 \%$ & 1.62 & 0.99 & 2.67 & 0.057 \\
\hline \multirow[t]{5}{*}{1 year } & 0.019 & $65-69$ & $1.8 \%$ & 0.87 & 0.72 & 1.03 & 0.112 \\
\hline & & $70-74$ & $1.8 \%$ & 0.95 & 0.80 & 1.12 & 0.518 \\
\hline & & $75-79$ & $1.9 \%$ & 0.90 & 0.76 & 1.06 & 0.192 \\
\hline & & $80-89$ & $1.9 \%$ & \multicolumn{2}{|c|}{ Reference group } & & \\
\hline & & $90+$ & $2.5 \%$ & 1.65 & 1.07 & 2.54 & 0.024 \\
\hline \multirow[t]{5}{*}{2 years } & 0.112 & $65-69$ & $2.5 \%$ & 0.91 & 0.78 & 1.07 & 0.252 \\
\hline & & $70-74$ & $2.6 \%$ & 0.98 & 0.84 & 1.13 & 0.743 \\
\hline & & $75-79$ & $2.6 \%$ & 0.99 & 0.86 & 1.15 & 0.928 \\
\hline & & $80-89$ & $2.6 \%$ & \multicolumn{2}{|c|}{ Reference group } & & \\
\hline & & $90+$ & $3.4 \%$ & 1.55 & 1.04 & 2.32 & 0.032 \\
\hline
\end{tabular}


Table 2. continued

\begin{tabular}{|c|c|c|c|c|c|c|c|}
\hline Outcome & Factor $\mathrm{p}$ value & Level (years) & Risk of events & HR & Lower HR & Upper HR & Level $p$ value \\
\hline \multirow[t]{5}{*}{5 years } & 0.341 & $65-69$ & $4.4 \%$ & 0.98 & 0.86 & 1.11 & 0.740 \\
\hline & & $70-74$ & $4.5 \%$ & 1.01 & 0.90 & 1.14 & 0.819 \\
\hline & & $75-79$ & $4.5 \%$ & 1.01 & 0.89 & 1.14 & 0.931 \\
\hline & & $80-89$ & $4.5 \%$ & \multicolumn{4}{|c|}{ Reference group } \\
\hline & & $90+$ & $6.0 \%$ & 1.43 & 0.99 & 2.06 & 0.054 \\
\hline \multirow[t]{5}{*}{10 years } & 0.508 & $65-69$ & $7.5 \%$ & 0.97 & 0.87 & 1.09 & 0.638 \\
\hline & & $70-74$ & $7.6 \%$ & 0.99 & 0.89 & 1.10 & 0.871 \\
\hline & & $75-79$ & $7.6 \%$ & 0.99 & 0.89 & 1.10 & 0.884 \\
\hline & & $80-89$ & $7.7 \%$ & \multicolumn{4}{|c|}{ Reference group } \\
\hline & & $90+$ & $10 \%$ & 1.33 & 0.93 & 1.90 & 0.116 \\
\hline \multicolumn{8}{|l|}{ Revision } \\
\hline \multirow[t]{5}{*}{0.5 years } & 0.144 & $65-69$ & $1.6 \%$ & 0.79 & 0.65 & 0.97 & 0.023 \\
\hline & & $70-74$ & $1.4 \%$ & 0.80 & 0.67 & 0.97 & 0.022 \\
\hline & & $75-79$ & $1.3 \%$ & 0.85 & 0.71 & 1.01 & 0.069 \\
\hline & & $80-89$ & $1.2 \%$ & \multicolumn{4}{|c|}{ Reference group } \\
\hline & & $90+$ & $0.92 \%$ & 0.89 & 0.48 & 1.65 & 0.710 \\
\hline \multirow[t]{5}{*}{1 year } & 0.335 & $65-69$ & $2.1 \%$ & 0.95 & 0.80 & 1.13 & 0.579 \\
\hline & & $70-74$ & $1.9 \%$ & 0.87 & 0.74 & 1.03 & 0.095 \\
\hline & & $75-79$ & $1.7 \%$ & 0.88 & 0.75 & 1.03 & 0.118 \\
\hline & & $80-89$ & $1.6 \%$ & \multicolumn{4}{|c|}{ Reference group } \\
\hline & & $90+$ & $1.3 \%$ & 0.74 & 0.40 & 1.37 & 0.339 \\
\hline \multirow[t]{5}{*}{2 years } & 0.206 & $65-69$ & $2.9 \%$ & 1.10 & 0.94 & 1.27 & 0.228 \\
\hline & & $70-74$ & $2.6 \%$ & 0.99 & 0.85 & 1.14 & 0.863 \\
\hline & & $75-79$ & $2.4 \%$ & 0.95 & 0.82 & 1.10 & 0.475 \\
\hline & & $80-89$ & $2.2 \%$ & \multicolumn{4}{|c|}{ Reference group } \\
\hline & & $90+$ & $1.8 \%$ & 0.69 & 0.38 & 1.25 & 0.219 \\
\hline \multirow[t]{5}{*}{5 years } & 0.010 & $65-69$ & $4.5 \%$ & 1.22 & 1.07 & 1.40 & 0.002 \\
\hline & & $70-74$ & $4.0 \%$ & 1.12 & 0.98 & 1.28 & 0.083 \\
\hline & & $75-79$ & $3.7 \%$ & 1.03 & 0.91 & 1.17 & 0.640 \\
\hline & & $80-89$ & $3.4 \%$ & \multicolumn{4}{|c|}{ Reference group } \\
\hline & & $90+$ & $2.7 \%$ & 0.74 & 0.44 & 1.25 & 0.254 \\
\hline \multirow[t]{5}{*}{10 years } & $<0.001$ & $65-69$ & $6.3 \%$ & 1.31 & 1.16 & 1.48 & $<0.001$ \\
\hline & & $70-74$ & $5.6 \%$ & 1.17 & 1.03 & 1.32 & 0.013 \\
\hline & & $75-79$ & $5.2 \%$ & 1.08 & 0.95 & 1.21 & 0.227 \\
\hline & & $80-89$ & $4.8 \%$ & \multicolumn{4}{|c|}{ Reference group } \\
\hline & & $90+$ & $3.8 \%$ & 0.77 & 0.46 & 1.28 & 0.316 \\
\hline
\end{tabular}

$\mathrm{HR}=$ hazard ratio; VTE = venous thromboembolism.

Databases can only provide an overview at a population level and fail to provide details at the individual patient level such as their functional situation, mental acuity, extent of their comorbid conditions, and home support system. Our analysis adjusted for various comorbidities and preexisting health conditions when comparing the outcomes between the octogenarians and the younger patients. However, these types of databases cannot provide guidance in terms of treatment strategies or policy because it cannot define the drivers of complications and readmissions in this population. Detailed studies at the institutional levels are necessary to identify the patient risk factors leading to increased risks postoperatively after primary THA.

The octogenarians in our study had a greater number of comorbid conditions than did patients in the younger cohort, perhaps leading to the observed increased risks of death and complications. Thirty percent of the octogenarian group in our study had a Charlson score of 3 or greater, whereas only $17 \%$ of the 65 - to 69 -year cohort had a score 
Fig. 4 An increased risk of 90day readmission was observed with older age.
Fig. 5 Kaplan-Meier survival showing a higher risk of dislocation with older age.
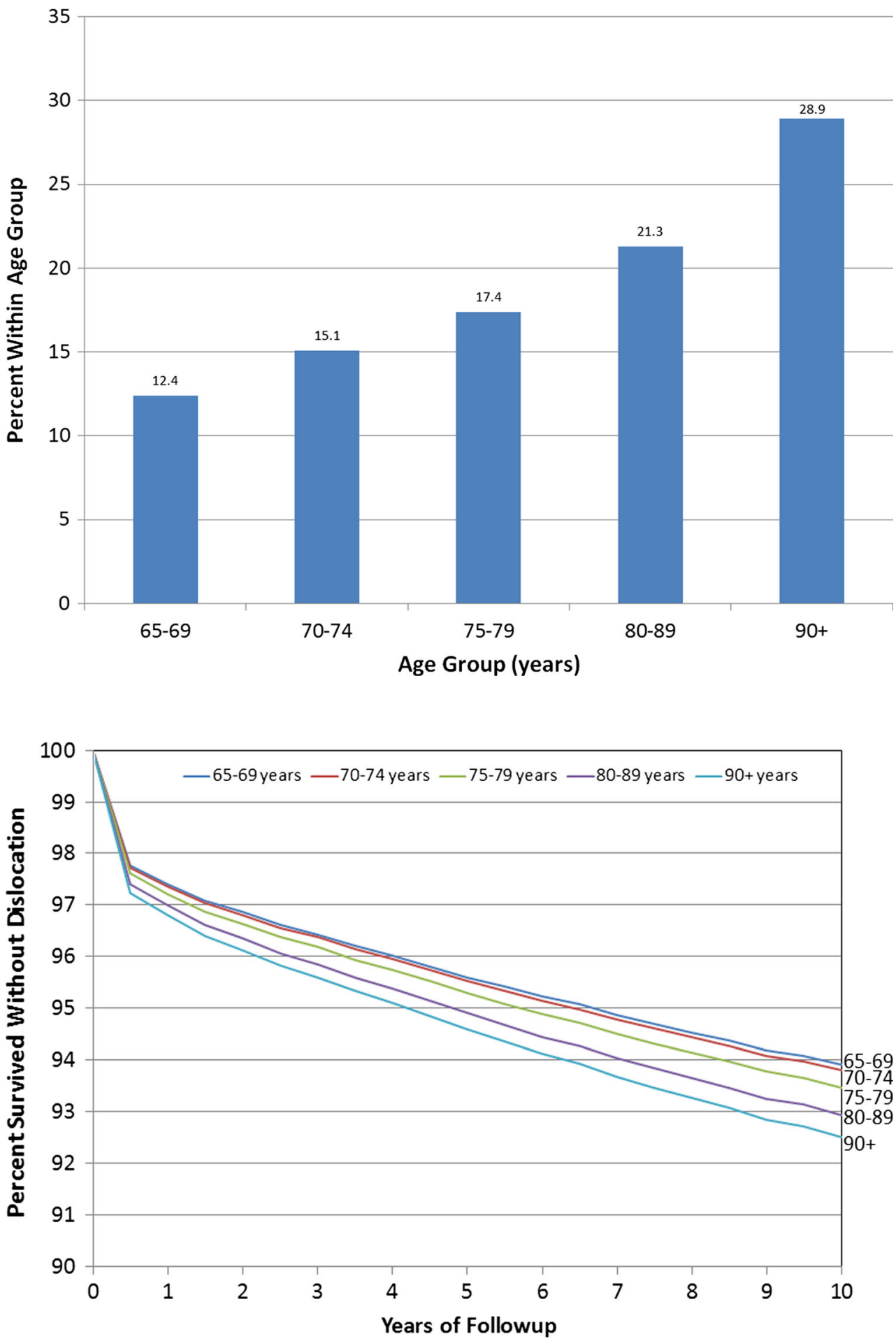

of 3 or greater. Several studies have also found high rates of postoperative medical complications in patients older than 80 years old undergoing total joint arthroplasty with the incidence ranging from $14 \%$ to as high as $77 \%$ [7, 13, 15, 20]. Kreder et al.'s [8] analysis of complications after either TKA or THA from the Canadian registry showed that octogenarians, compared with the control group composed of 65 to 79 year olds, had an increased incidence of major and minor complications. The mortality rate after THA was found to be 4.4 times higher, the risk of myocardial infarct was 2.7 times higher, and there was a 3.5-fold increased risk in pneumonia. Our results found that 
the risk of mortality was higher for octogenarians when compared with all younger cohorts at all time points. Our data demonstrated an increased incidence of perioperative complications with increased comorbid conditions similar to other studies $[8,13,16]$.

The octogenarians in our study had a $30 \%$ greater risk of VTE at 10 years when compared with the younger $65-$ to 69 -year cohort. The increased risk of VTE in the octogenarians is likely a multifactorial problem, including factors such as a more sedentary lifestyle compared with younger patients and perhaps dysfunction of the coagulation cascade as patients age [1]. Given the increased risk of VTE in the octogenarian, strategies need to be developed for improved VTE prophylaxis such as adequate chemical and mechanical prophylaxis, early mobilization, and greater postoperative surveillance. If increased numbers of octogenarians are being discharged to nursing homes, studies are required to determine whether there are adequate resources at these facilities to provide for the greater attention this group of patients requires to minimize postoperative complications such as VTE.

In this study, there was a $16 \%$ increased risk of dislocation in the octogenarians when compared with the 65- to 69 -year cohort. Prior studies have found the incidence of dislocation after primary THA to range from $4 \%$ to $15 \%$ $[9,13]$. With the advent of larger femoral head sizes, capsular repair, and newer approaches, dislocation rates have decreased $[4,18]$. The etiology of the increased dislocation incidence in the octogenarian undergoing primary THA likely is multifactorial and may include lax capsular structures, weak musculature, impaired proprioception, and cognitive problems that may predispose them to a higher risk of dislocation. We did not find any increased risk of $\mathrm{PJI}$ in the octogenarian when compared with the younger age group we studied.

The increased incidence of octogenarians undergoing primary THA over this study period by approximately $81 \%$ places a substantial burden on our already fragile healthcare system. To improve outcomes and help decrease the costs of this increased total joint replacement volume, the BPCI program was initiated to hold institutions and providers more accountable for the delivery of care. The BPCI initiative has been shown to improve overall patient care and decrease healthcare costs in some instances [3]. Identifying patients at greater risk for complications and readmission and appropriately educating and managing them preoperatively through an algorithmic approach to maximize their healthcare status is critical to the success of this value-based healthcare model. In large part, the institutions realize savings when patients are discharged to home as opposed to a nursing home or rehabilitation facility. Institutions are therefore encouraged to educate patients and manage their medical comorbidities before surgery with the goal of decreasing surgical complications. However, if patients are readmitted or have complications, then the cost of the added service to the patient is in large part absorbed by the institution.

Our study identified an increased frequency of complications, readmissions, and discharge status to nursing homes in a subset of elderly Medicare patients undergoing primary THA. Seventy-three percent of octogenarians were discharged to either a nursing home or rehabilitation facility compared with only $38 \%$ of the 65 - to 69 -year-old group. A total of $21 \%$ of the octogenarians were readmitted within 90 days of surgery compared with $12 \%$ for patients in the younger (65-69 years old) group. This has implications for institution providing THA to the elderly. A $21 \%$ readmission incidence would place the overall bundled payment program at jeopardy at these institutions if the entire cost of the readmission was absorbed by these institutions. Because octogenarians are at increased risk of dislocation, VTE, medical complications, and mortality after THA, value-based care models that penalize hospitals for readmissions and complications may inadvertently result in loss of access to care for this group of patients as a result of the financial makeup of these bundled care models.

The success of the BPCI is in large part dependent on delivering quality care to minimize the incidence of readmission and complications. The model has to be fair for all stakeholders involved in the delivery of care and sharing in the risks. The BPCI has several positive aspects that incentivize institutions to develop a program to improve overall patient outcomes. Programs are now sensitized to identifying high-risk patients undergoing THA and managing their medical conditions before surgery. Based on our study, we feel all elderly Medicare patients should undergo risk stratification and, if deemed to be of high risk, should all undergo preoperative medical clearance. Despite a well-developed preoperative program to improve health before surgical intervention, there are inherent increased risks leading to readmissions and complications in the octogenarian as a result of their comorbid conditions, which need to be considered or accounted for in the BPCI model. With the increased complications and readmission rates in the octogenarian, the BPCI program may also inadvertently penalize those institutions with a greater burden of providing care for Medicare beneficiaries older than 80 years of age.

The BPCI program has recently been implemented and requires further modification and needs to evolve as additional data become available. Collective discussions among stakeholders involved with the BPCI program should identify strategies and formulas to account for the added complications and readmissions in the octogenarian. This could include changes in the payment structure with 
multipliers to include age, extent of comorbid conditions, and socioeconomic status. Other options could include limiting the downside risks based on the same factors.

Value-based care models were developed to improve care and decrease healthcare costs, but may have unintended consequences in the octogenarian. To try to prevent this from happening to this vulnerable patient population, bundled care programs need to further evolve and allow for modifications to its inherent structure by gathering data on an ongoing basis on performance, outcomes, and overall costs to the program and institutions providing care. With increased life expectancy and more elderly patients undergoing primary THA, age alone should not be the limiting factor when considering surgical intervention despite the anticipated increased complications in this group. For continued success, the BPCI program needs to evolve and allow for risk stratification in the overall payment formula to account for increased age and comorbid conditions to avoid unintended consequences and promote continued participation at institutions caring for the elderly seeking THA.

\section{References}

1. Abbate R, Prisco D, Rostagno C, Boddi M, Gensini GF. Agerelated changes in hemostatic system. Int J Clin Lab Res. 1995;23:1-3.

2. Bozic K, Lau E, Ong K, Vail T, Rubash H, Berry D. Comparative effectiveness of metal-on-metal and metal-on-polyethylene bearings in Medicare total hip arthroplasty patients. J Arthroplasty. 2012;27:37-40.

3. Froimson M, Rana A, White R, Marshall A, Schutzer S, Healy W, Naas P, Daubert G, Iorio R, Parsley B. Bundled Payments for Care Improvement Initiative: the next evolution of payment formulations. AAHKS Bundled Payment Task Force. J Arthroplasty. 2013;28:157-165.

4. Hedley AK, Hendren DH, Mead LP. A posterior approach to the hip joint with complete posterior capsular and muscular repair. $J$ Arthroplasty. 1990;5(Suppl):S57-S66.

5. Jin F, Chung F. Minimizing perioperative adverse events in the elderly. Br J Anaesth. 2001;87:608-624.
6. Jones CA, Voaklander DC, Johnston WC, Suarez-Almazor ME. The effect of age on pain, function, and quality of life after total hip and knee arthroplasty. Arch Intern Med. 2001;161:454-460.

7. Keisu KS, Orozco F, Sharkey PF, Hozack WJ, Rothman RH, McGuigan FX. Primary cementless total hip arthroplasty in octogenarians. J Bone Joint Surg Am. 2001;83:359-363.

8. Kreder HJ, Berry GK, McMurty IA, Halman SI. Arthroplasty in the octogenarian: quantifying the risks. $J$ Arthroplasty. 2005;20:289-293.

9. Levy RN, Levy CM, Snyder J, Digiovanni J. Outcome of longterm results following total hip replacement in elderly patients. Clin Orthop Relat Res. 1995;316:25-30.

10. Lubbeke A, Roussos C, Barea C, Kohnlein W, Hoffmeyer P. Revision total hip arthroplasty in patients 80 years or older. $J$ Arthroplasty. 2012;27:1041-1046.

11. Mahomed N, Barrett J, Katz J, Phillips C, Losina E, Lew R, Guadagnoli E, Harris W, Poss R, Baron J. Rates and outcomes of primary and revision total hip replacement in the United States Medicare population. J Bone Joint Surg Am. 2003;85:27-32.

12. Mota RE. Cost-effectiveness analysis of early versus late total hip replacement in Italy. Value in Health. 2013;16:267-279.

13. Newington DP, Bannister GC, Fordyce M. Primary total hip replacement in patients over 80 years of age. J Bone Joint Surg Br. 1990;72:450-452.

14. Ong KL, Kurtz SM, Lau E, Bozic KJ, Berry DJ, Parvizi J. Prosthetic joint infection risk after total hip arthroplasty in the Medicare population. J Arthroplasty. 2009;24:105.

15. Parvizi J, Pour AE, Keshavarzi NR, D’Apuzzo M, Sharkey PF, Hozack WJ. Revision total hip arthroplasty in octogenarians. A case-control study. J Bone Joint Surg Am. 2007;89:2612-2618.

16. Phillips TW, Grainger RW, Cameron HS, Bruce L. Risks and benefits of elective hip replacement in the octogenarian. CMAJ. 1987; 137:497-500.

17. Riley SA, Spears JR, Smith LS, Mont MA, Elmallah RK, Cherian JJ, Malkani AL. Cementless tapered femoral stems for total hip arthroplasty in octogenarians. J Arthroplasty. 2016 May 12. [Epub ahead of print].

18. Stroh DA, Issa K, Johnson AJ, Delanois RE, Mont MA. Reduced dislocation rates and excellent functional outcomes with largediameter femoral heads. J Arthroplasty. 2013;28:1415-1420.

19. Thomasson E, Caux I, Guingand O, Terracher R, Mazel C. Total hip arthroplasty for osteoarthritis in patients aged 80 years or older: influence of co-morbidities on final outcome. Orthop Traumatol Surg Res. 2009;95:249-253.

20. Wurtz LD, Feinberg JR, Capello WN, Meldrum R, Kay PJ. Elective primary total hip arthroplasty in octogenarians. $J$ Gerontol A Biol Sci Med Sci. 2003;58:M468-M471. 